\title{
Relationships between perfusion defects and static brain scan positivity in patients with ischaemic completed stroke: considerations about the origin of the increased uptake
}

\author{
ALFREDO BARTOLINI \\ From the Department of Clinical Neurology, University of Genoa, Italy
}

SUMMARY The relation between perfusion defects shown by radionuclide angiography and static brain scan positivity was evaluated in patients with ischaemic completed stroke at various intervals from the onset of symptoms. An inverse relation between radionuclide angiography and static scan positivity was found for the period within 15 days of the onset of symptoms. The possible relation between changes in perfusion and static brain scan positivity is discussed.

An increase of vascularity and disruption of the blood brain barrier are held to be responsible for increased uptake in radionuclide brain scans of patients with cerebral lesions. ${ }^{12}$ Blood brain barrier disturbance, which has been shown to be the most important factor in tumours, ${ }^{2-5}$ is probably also the critical factor in vascular lesions.

Increased uptake appears only in a proportion of ischaemic patients and is characterised by typical temporal sequential changes ${ }^{6-9}$ suggesting a relationship with the progress of neovascularization around the area of the infarct. ${ }^{10}$ The prognostic and functional significance of these changes is still debatable. ${ }^{11-13}$

Coupling static brain scans with radionuclide intravenous angiography permits an analysis of the relationship between perfusion changes and increased uptake, and may help to elucidate the interactions between blood flow rate changes and barrier integrity in cerebral vascular lesions. The aim of this study was to evaluate the combined diagnostic efficiency of intravenous radionuclide cerebral angiography and static brain scans in patients affected by ischaemic completed stroke.

\begin{abstract}
Address for reprint requests: Dott Alf redo Bartolini, Clinica Neurologica, dell'Università Via de Toni 516132 Genoa, Italy
\end{abstract}

Received 15 July 1981 and in revised form 10 October 1981 Accepted 19 October 1981

\section{Patients and method}

One hundred and fourteen patients with cerebral ischaemic completed strokes were studied. Diagnosis was according to the criteria established by Marshall, ${ }^{14}$ and was confirmed by computed tomography in 108 cases and by cerebral angiography in 32 cases. Patients underwent both intravenous radionuclide angiography and static brain scans at various time-intervals from the onset of symptoms; in 30 cases both examinations were repeated at random intervals.

Examination procedure Radionuclide angiography was performed with the patient in the usual supine anteroposterior position. After the bolus injection of approximately $10-15 \mathrm{mCi}$ of ${ }^{99} \mathrm{mTc}$ pertechnetate into a brachial vein, sequential pictures were taken, at $2 \mathrm{~s}$ intervals for approximately $40 \mathrm{~s}$. After the completion of the sequence a static brain scan was performed (early scan) and was repeated after an interval of 4-6 hours (delayed scan).

The detection equipment was a gamma camera (Pho Gamma HP Nuclear Chicago); pictures were taken, for radionuclide angiography, with a $35 \mathrm{~mm}$ motor drive time lapse Nikon camera attached to the oscilloscope of the scintillation camera. A photodensitometer (sensor surface $2.5 \mathrm{~mm}^{2}$ ) which sequentially scanned the pictures in the same previously selected positions was used to generate time-activity curves from six symmetrical areas on each hemisphere as described elsewhere. ${ }^{15}$ From sequential photodensitometric values for each explored region, fed off-line to a computer (Mitra $15 \mathrm{Cii}$ ), time activity curves were obtained by comparing with the values obtained by test pictures taken with the same detection equipment and accumulating a known 
number of counts. These corrected values were used for best fitting operations, determination of the time of maximal counting rate, and for deriving the integral of the functions up to this time. Following the onset of detected activity, regional time-activity curves are characterised by an initial rapid increasing portion followed by a peak and a slower decreasing limb. As long as the function is increasing, monitored activity is mainly representative of tracer input into monitored space; the area under the upslope may be taken as proportional to regional blood flow rate. ${ }^{16}$ Comparison of blood flow rates in symmetrical region pairs was performed by calculating the integrated counting rates relative to each region up to time of maximal activity (area under the upslope), and expressing symmetry of perfusion by an index obtained by subtracting area value on the healthy side from that on the injured side dividing by their sum. Fifty normal subjects were studied in order to determine the limits of perfusion symmetricity: the mean value of this index was $0.054 \pm 0.021$ (mean $\pm \mathrm{sd}$ ). A value exceeding 0.096 (mean \pm 2SD.) was taken as expressing asymmetrical perfusion.

\section{Results}

The static brain scan was positive in 68 of 141 examinations $(48 \%)$. Radionuclide angiography detected asymmetrical perfusion in 102 of 141 examinations $(72 \%)$. In 85 examinations $(60 \%)$ a decreased perfusion was found on the affected side; in 17 examinations $(12 \%)$ a paradoxically increased perfusion on the affected side was found. Affected region pairs were 319 out of $846(37 \%) ; 281(33 \%)$, were characterised by decreased perfusion on the affected side, and $38(4 \%)$ by paradoxically increased perfusion.

In table 1 the incidence of perfusion defects at the time of the static brain scan are indicated as a function of time from onset of symptoms separately for both brain scan negative and positive examinations.

The incidence of perfusion defects for negative static examinations was $77 \%$ in the initial days following the stroke, and decreased slowly with time from the onset. For positive static examinations, the incidence of perfusion defects started with a value of $25 \%$ in the initial days following the stroke, and increased thereafter. In a 0-15 days interval there was a significant prevalence of perfusion defects in patients with negative static examinations: this difference disappeared for examinations performed after this time.

Table 1 Relationships between static scan positivity and perfusion data obtained with radionuclide angiography at various time-intervals from onset of symptoms. Chi square test was performed between absence and presence of perfusion defects, ie grouping together symmetrical and increased perfusion.

\begin{tabular}{|c|c|c|c|c|c|}
\hline & & $\begin{array}{l}\text { Days from } \\
\text { onset }\end{array}$ & $\begin{array}{l}\text { Static Scan } \\
\text { Positive }\end{array}$ & Negative & Chi square \\
\hline \multirow{7}{*}{ Radionuclide angiography. Perfusion on affected side } & $\begin{array}{l}\text { Increased } \\
\text { Decreased } \\
\text { Symmetrical } \\
\text { No }\end{array}$ & $0-5$ & $\begin{array}{l}2 \\
225 \% \\
4 \\
2\end{array}$ & $\begin{array}{l}3 \\
1777 \% \\
2 \\
22\end{array}$ & $\begin{array}{l}\chi^{2}=9.33 \\
p<0.01\end{array}$ \\
\hline & $\begin{array}{l}\text { Increased } \\
\text { Decreased } \\
\text { Symmetrical } \\
\text { No }\end{array}$ & $5-10$ & $\begin{array}{l}1 \\
430 \% \\
8 \\
13\end{array}$ & $\begin{array}{l}1 \\
675 \% \\
1 \\
8\end{array}$ & $\begin{array}{l}\chi^{2}=5.85 \\
p<0.05\end{array}$ \\
\hline & $\begin{array}{l}\text { Increased } \\
\text { Decreased } \\
\text { Symmetrical } \\
\text { No }\end{array}$ & $10-15$ & $\begin{array}{l}2 \\
440 \% \\
4 \\
10\end{array}$ & $\begin{array}{l}0 \\
675 \% \\
2 \\
8\end{array}$ & $\begin{array}{l}\chi^{2}=3.85 \\
\mathrm{p}<0.05\end{array}$ \\
\hline & $\begin{array}{l}\text { Increased } \\
\text { Decreased } \\
\text { Symmetrical } \\
\text { No }\end{array}$ & $15-25$ & $\begin{array}{l}0 \\
975 \% \\
3 \\
12\end{array}$ & $\begin{array}{l}1 \\
763 \% \\
3 \\
11\end{array}$ & $\begin{array}{l}\chi^{2}=0.019 \\
\mathrm{p}=\mathrm{NS}\end{array}$ \\
\hline & $\begin{array}{l}\text { Increased } \\
\text { Decreased } \\
\text { Symmetrical } \\
\text { No }\end{array}$ & $25-35$ & $\begin{array}{l}1 \\
770 \% \\
2 \\
10\end{array}$ & $\begin{array}{l}1 \\
240 \% \\
2 \\
5\end{array}$ & $\begin{array}{l}\chi^{2}=0.31 \\
\mathrm{p}=\mathrm{NS}\end{array}$ \\
\hline & $\begin{array}{l}\text { Increased } \\
\text { Decreased } \\
\text { Symmetrical } \\
\text { No }\end{array}$ & $35-60$ & $\begin{array}{l}2 \\
550 \% \\
3 \\
10\end{array}$ & $\begin{array}{l}2 \\
562 \% \\
1 \\
8\end{array}$ & $\begin{array}{l}\chi^{2}=0.045 \\
p=N S\end{array}$ \\
\hline & $\begin{array}{l}\text { Increased } \\
\text { Decreased } \\
\text { Symmetrical } \\
\text { No }\end{array}$ & $>60$ & $\begin{array}{l}0 \\
480 \% \\
1 \\
5\end{array}$ & $\begin{array}{l}0 \\
872 \% \\
3 \\
11\end{array}$ & $\begin{array}{l}\chi^{2}=0.09 \\
\mathrm{p}<\mathrm{NS}\end{array}$ \\
\hline
\end{tabular}


The figure indicates the time-course of incidence of static brain scan positivity in subjects selected according to the presence or absence of perfusion defects at the time of static scan performance. Patients with perfusion defects exhibited an increasing incidence of positivity, which peaked at about 30 days after the onset of symptoms and decreased afterwards. Peak incidence in this group, was $77 \%$, corresponding to $46 \%$ of the whole number of examinations performed at this time. Patients with no perfusion defects exhibited a similar increasingdecreasing pattern, but peak incidence was earlier, at 5-10 days. Peak incidence, in this group was $75 \%$, corresponding to $42 \%$ of all examinations performed at this time.

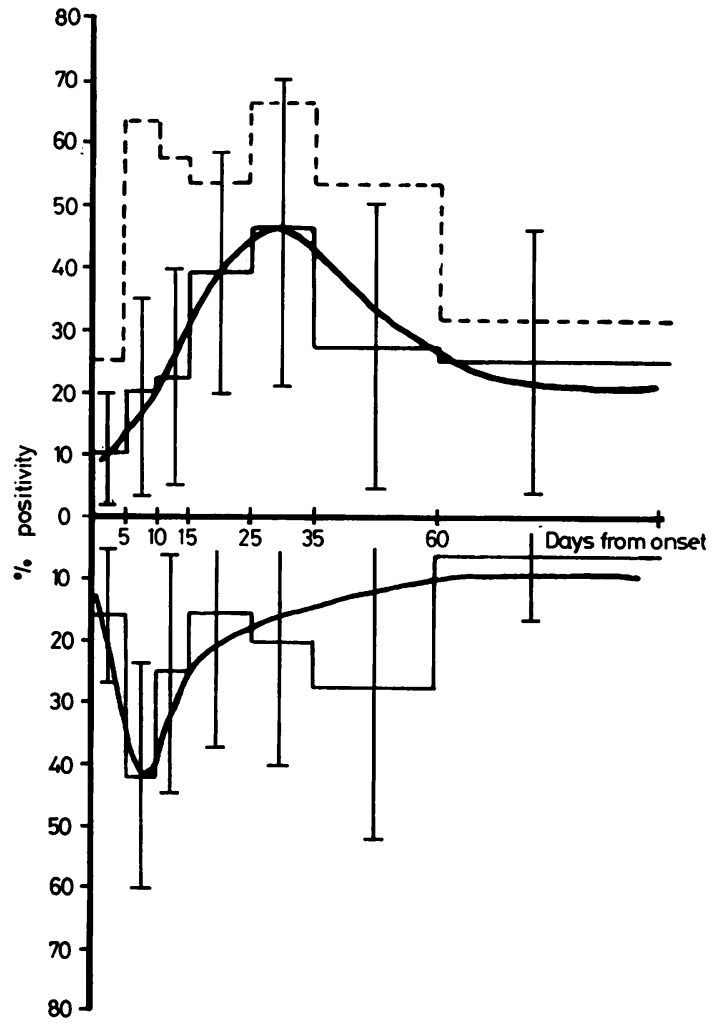

Fig Time course of incidence of static scan positivity in patients with (top) and without (bottom inverted scale) perfusion defects at the time of static scan performance. Global incidence of positivity is indicated by the dotted line, vertical bars represent $95 \%$ confidence limits.

TIME COURSE OF PERFUSION DEFECTS For 30 patients follow up examinations were performed at random intervals. They fell into four patterns, according to the sequence of perfusion findings: perfusion defect followed by absence of perfusion defect (Yes-No pattern); absence of perfusion defect followed by perfusion defect (NoYes pattern), perfusion defect at both examinations (Yes-Yes pattern), absence of perfusion defect at both examinations (No-No pattern.) Patients with paradoxically increased perfusion on the affected side were considered not to have perfusion defects.

In table 2, the frequency and temporal characters of the various patterns are shown: it may be noted that (a) 11 out of 16 patients $(68 \%)$ presenting with no perfusion defect at one examination exhibited decreased perfusion at the other, (b) Yes-No and No-Yes patterns were present in nearly the same number of cases, (c) patients with changing perfusion patterns (Yes-No and No-Yes) had, at the second static examination, a greater incidence of abnormality $(80 \%)$ than patients with unchanging perfusion defect $(42 \%)$.

\section{Discussion}

The data showed a time-dependent negative relationship between perfusion defects detected with radionuclide angiography and increased uptake in the static brain scan. This inverse relationship was significant during the 15 days from the onset of symptoms and subsequently faded away.

In a patient suffering from ischaemic brain disease, the absence of perfusion defects at radionuclide angiography may be either a steady or a transient condition. Constant normal perfusion may occur when symptoms developed on an haemodynamic basis without detectable changes of blood flow, or when restoration of flow occurred owing to the neovascularisation of the infarcted area ${ }^{10}$ or to the re-perfusion of previously occluded vessels. ${ }^{17}$ Transient normal perfusion may occur when there is an increase of blood flow in the affected region from vasodilatation, resulting from impaired autoregulation or increased $\mathrm{CO}_{2}$ concentration. ${ }^{18}$

From the analysis of sequential changes of perfusion, it may be suggested that, at least in some of the patients, both symmetrical perfusion and paradoxical hyperperfusion may result from the same transient increase of blood flow in the ischaemic focus. In fact, 11 (five with hyperperfusion and six with symmetrical perfusion) of 16 patients in whom no perfusion defect was detected on the affected side on one examination, showed decreased perfusion in the other study; in particular, decreased perfusion preceded or followed absence of perfusion defects in nearly the same number of cases. It is possible that, in these cases, symmetrical perfusion is a less evident manifestation of the paradoxical hyper- 
Table 2 Frequency and temporal characters of sequential changes of perfusion in 30 subjects undertaking follow up study.

\begin{tabular}{|c|c|c|c|c|}
\hline & $\begin{array}{l}\text { Patterns } \\
\text { No-No }\end{array}$ & $\begin{array}{l}\text { f perfusion } \\
\text { Yes-Yes }\end{array}$ & Yes-No & No-Yes \\
\hline No & 5 & 14 & 5 & 6 \\
\hline $\begin{array}{l}\text { Mean time of 1st } \\
\text { examination (days) }\end{array}$ & 19 & 13 & 4 & 6 \\
\hline $\begin{array}{l}\text { Mean time 2nd } \\
\text { examination (days) }\end{array}$ & 26 & 25 & 15 & 13 \\
\hline $\begin{array}{l}\text { Static scan positive 1st } \\
\text { examination }\end{array}$ & $480 \%$ & $428 \%$ & $120 \%$ & $460 \%$ \\
\hline $\begin{array}{l}\text { Static scan positive } 2 \text { nd } \\
\text { examination }\end{array}$ & $480 \%$ & $642 \%$ & $480 \%$ & $583 \%$ \\
\hline
\end{tabular}

perfusion sometimes observed at radionuclide angiography ${ }^{19-21}$ reflecting a luxury perfusion syndrome. ${ }^{22}$

A relation between transient hyperperfusion and increased uptake may be suggested by the fact that patients with no perfusion defect had an earlier peak positivity in the static scan than patients with perfusion defects; moreover patients with a changing perfusion pattern had a greater incidence of increased uptake than patients with an unchanging pattern. This relation may be due to (a) increased vascularity, implying that the increased uptake is due to the increased amount of tracer pooled in the lesion vascular space, or to (b) increased tracer availability implying that both scan positive and negative patients had the same degree of blood brain barrier impairment that became evident when sufficient flow was present or, finally, to (c) long lasting barrier damage produced by the change of blood flow. This last hypothesis seems more probable since the small representation (3-4\%) of vascular space in the tissue monitored, ${ }^{23}$ and the presence of a large amount of normally extravasated activity in the extracerebral cranial tissues, ${ }^{24}$ hampers the detection of vascular volume changes at the static scan unless they are quite large, as in vascular malformation. Moreover in cases with changing perfusion patterns at the follow up study (No-Yes or Yes-No), increased uptake did not follow the changes of perfusion; in particular, in patients with No-Yes pattern, increased uptake did not disappear when a perfusion defect was detected at the second examination. This suggests that long lasting blood brain barrier damage, the consequence of an abrupt change of blood flow rate, may be the main factor causing the increased uptake, at least in patients with positive static scans within 15 days from onset of symptoms. Effects of abrupt recirculation following ischaemia on blood brain barrier integrity have been extensively studied by several authors ${ }^{25-29}$ and it has been suggested that transient increases of blood flow in an ischaemic focus may cause long lasting blood brain barrier damage.
In conclusion, by evaluating separately, the incidence of positivity in the static brain scan in patients grouped according to the presence or absence of perfusion defects at radionuclide angiography, two different temporal distributions of positivity can be considered: one characterised by peak positivity at about 10 days from the onset of symptoms, the other by a peak positivity at about 30 days. The former was typical of patients showing no perfusion defect at the radionuclide angiography, the latter corresponded to patients showing perfusion defects at the time of static brain scans. Two possible different mechanisms subserving the increased uptake of pertechnetate in cerebral vascular lesions can be considered: one characterised by an early blood brain barrier disruption resulting from an abrupt change of blood flow, the other by a more delayed blood brain barrier involvement possibly reflecting the presence of immature newly formed vessels devoid of a functioning blood brain barrier. The suggestion that a negative radionuclide angiography-positive static scan pattern is suggestive of a tumour must be considered with caution: repetition of a negative dynamic study with a positive static scan is recommended.

\section{References}

${ }^{1}$ Penning L, Front D, Bechar M, Go KG, Rodermond JM. Factors governing the uptake of pertechnetate by human brain tumours. Brain 1973;96:225-34.

${ }^{2}$ Front D. Scintigraphic assessment of vascularity and blood tissue barrier of human brain tumours. $J$ Neurol Neurosurg Psychiatry 1977;41:18-23.

3 Bakay L. Basic aspects of brain tumor localization by radioactive substances. $J$ Neurosurg 1967;27:239-45.

4 Bakay L. The extracellular space in brain tumours: morphological considerations. Brain 1970;93:693-8.

${ }^{5}$ Bar Sella P, Front D, Hardoff R, Peyser E, Borovich B, Nir I. Ultrastuctural basis for different Pertechnetate uptake patterns by various human brain tumors. J Neurol Neurosurg Psychiatry 1979;42:924-30.

${ }^{6}$ Glasgow JL, Curriers RD, Goodrich JK, Tutor FT. Brain scans of cerebral infarcts with radioactive mercury. Radiology 1967;98:1086-91. 
${ }^{7}$ Molinari GF, Pircher F, Heyman AV. Serial brain scanning using Technetium $99 \mathrm{~m}$ in patients with cerebral infarction. Neurology (Minneap) 1967;17: 627-36.

${ }^{8}$ Usher ML, Quinn JL. Serial brain scanning with Technetium ${ }^{99 m}$ Pertechaetate in cerebral infarction. Am J Ronengtenol 1969;105:728-33.

${ }^{9}$ Verhas M, Schoutens A, Dermol O et al, Study in cerebrovascular disease: brain scanning with technetium ${ }^{99 m}$ pertechnetate, clinical correlations. Neurology (Minneap) 1975;2d :553-8.

${ }_{10}$ Di Chiro G, Timins L, Jones AE, Johnston GS, Hammock MK, Swann S. Radionuclide scanning and microangiography in evolving and completed brain infarction. Neurology (Minneap) 1974;24:41823.

11 Gutterman P, Shenkin H. Cerebral scans in completed stroke: value in prognosis of clinical course. $\mathrm{J} \mathrm{Am}$ Med A 1969;207:145-7.

12 Marshall J, Popham MG. Radioactive brain scanning in the management of cerebrovascular disease. $J$ Neurol Neurosurg Psychiatry 1970;32:201-4.

${ }^{13}$ Narva EV, Sonninen V. The prognostic significance of brain scanning and rapid sequential scintigraphy in carotid artery cerebral infarction. Acta Neurol Scand 1978; Suppl 67: 352-3.

${ }^{14}$ Marshall J. The Management of cerebrovascular disease. Oxford: Blackwell, 1976:66-86.

${ }^{15}$ Bartolini A, Di Pede E, Arcuri T. Regional cerebral mode transit time and the derivative of the regional cerebral function recorded for intravenous administration of a non diffusible tracer. Invest Radiol 1979;14:250-4.

${ }^{16}$ Moses DC, Natarajan TK, Previosi TJ, Udvardhely GB, Wagner NN jr. Quantitative cerebral circulation studies with sodium pertechnetate. J Nucl Med 1973; 14:142-58.

${ }^{17}$ Fieschi C, Bozzao L. Transient embolic occlusion of the middle cerebral and internal carotid arteries in cerebral apoplexy. J Neurol Neurosurg Psychiatry 1979;32:236-40.

18 Paulson OB. Cerebral apoplexy (stroke): pathogenesis pathophysiology and therapy as illustrated by regional blood flow measurements in the brain. Stroke $1971 ; 2: 327-60$.

${ }^{19}$ Snow RM, Keys JV. The luxury perfusion syndrome following cerebrovascular accident demonstrated by radionuclide angiography. $\mathrm{J} \mathrm{Nucl}$ Med 1974;15: 907-9.

${ }^{20}$ McKay WJ, Andrews JT, Mathur KS, Vascular cerebral infarctions demonstrated by serial gamma camera scintiphotography. Br J Radiol 1976;49:600-

${ }^{21}$ Soin JS, Burdine JA. Acute cerebral vascular accident associated with hyperperfusion. Radiology 1976;119: 109-12.

${ }^{22}$ Lassen NA. The luxury perfusion syndrome and its possible relation to acute metabolic acidosis localized in the brain. Lancet 1966;2:1113-5.

${ }^{23}$ Grubb RL jr, Phelps ME, Ter Pogossian MM. Regional cerebral blood volume in humans Arch Neurol 1973; 28:38-44.

${ }^{24}$ Oldendorf WH, Iisaka Y. Interference of scalp and skull with external measurement of brain isotope content: part I isotope content of scalp and skull. J Nucl Med 1969;10:177-83.

${ }^{25}$ Hossmann KA, Olsson $Y$. The effect of transient cerebral ischemia on vascular permeability to protein tracers. Acta Neuropathol 1971;18:89-102.

${ }^{26}$ Ito U, Ohno K, Nakamura N, Suganuma F, Inaba I. Brain edema during ischaemia and after restoration of blood flow: measurement of water, sodium, potassium content and plasma protein permeability. Stroke 1979;10:542-7.

${ }^{27}$ Mchedlishvili G, Kapuscinski A, Nikolaishvili L. Mechanisms of postischemic brain edema: contribution of circulatory factors. Stroke 1976;7:410-16.

${ }^{28}$ Haggendall E, Johansson B. Effect of increased intravascular pressure on the blood brain barrier to proteins in dogs. Acta Neurol Scand 1972;18:271-5.

29 Johansson B. Blood brain barrier disfunction in acute arterial hypertension after papaverine induced vasodilatation. Acta Neurol Scand 1974;20:573-80. 